\title{
A USER EXPERIENCE BASED APPROACH FOR EXPLORING PRODUCT DESIGN
}

\author{
Asikhia, O.K. ${ }^{1}$ \\ ${ }^{I}$ Chieflecturer, Department of Mechanical Engineering, Edo State Polytechnic, Usen, Edo State Nigeria \\ Oviawe, C.I. ${ }^{2}$ \\ ${ }^{2}$ Senior lecturer, Department of Mechanical Engineering, Edo State Polytechnic, Usen, Edo State Nigeria
}

\author{
Aigbomian S.E. ${ }^{3}$ \\ ${ }^{3}$ Senior Lecturer, Department of Business Studies, Edo State Polytechnic, Usen, Edo State Nigeria
}

DOI: $\underline{\text { https://doi.org/10.36713/epra3565 }}$

\begin{abstract}
When users are confronted with the use of a tool, they develop a mental model of how the product should function. The usability of products can be improved by incorporating features that are beneficial in the context of use to aid the user in completing the task. This paper reports series of studies that explores the concept of users experience as a concept for exploring product design. An alarm clock was chosen to explore the concept in the study. Thirty six participants were recruited in study 1 and they were provided with structured questionnaire to complete. This was done in order to obtain deep insights into the user's need. The identified needs from the structured questionnaire were collated and thereafter converted to engineering characteristics. These were later presented to another set of twenty five participants recruited to rank their importance in study 2. The ranking were averaged using the normalized weighting approach. At the end of the second study, a new prototype of the alarm clock was designed based on the five most important characteristics identified in the study. Finally, the alarm clock develop was compared with the conventional alarm clock available in the market using twenty participants recruited for study 3. The result shows the alarm clock developed from the study show significant performance rating compare to the conventional available in the market by the majority of the participants recruited in the study.

KEYWORDS: User experience, Product design, Users need, Engineering characteristics, Normalised weighting approach
\end{abstract}




\section{INTRODUCTION}

Multifunctional products have penetrated all aspects of our life. It was once estimated that each person in the Western world uses some twenty thousand different objects (each with its own interface), most of which are highly specialised and require learning (Norman, 1993). New interfaces with ever-more sophisticated features and functionality appear every day. This trend has a negative impact on users, as unfamiliar interfaces increase the cognitive effort required during interaction with products (Blackler et al., 2010). Over the last decade, the problem has been aggravated due to market demands and high consumer expectations.

Balancing these high functional expectations and the correct interpretation of the product features by consumers are often difficult to meet when several technologies are located in the same device (Asikhia et al., 2015). For example, mobile phones have been equipped with different functionality comprising games, cameras and various softwares. Providing documentation cannot address the problem of clear expressive intent in product as it has been found that people try things out on their own and try to relate what they already know to the current situation (Rettig, 1991). They are also likely not to attend any training classes to learn about the product. If the device is designed in accordance with the product form the user is familiar with, the need for training will be reduced.

In a typical product design process, understanding users' needs is one of the most essential tasks in design concept generation. The user centred based design approach primarily puts the users at the centre point of the design. In order to obtain a good understanding of the user's needs, it is essential to obtain how the end users of the product interact with the product to gain insight into the user thinking.

The work intends to contribute to research in the design community by highlighting the benefits of using the Voice of Customers (VoC) as the building blocks of the design process. While several innovative designs have sprung up in the design community, only few put the interest of the users in the centre point of their design. In order words, most of the products available in the market, users are expected to vary their cognitive abilities while using the product instead of the product to fit into their thinking. This is a critical shortcoming in the design community. The methodology adopted in this study has the potential to build a strong product user relationship if the observed behaviour is accommodated into the design of the product. This in turn could optimise the product life cycle.

\section{BACKGROUND STUDY}

'User experience' is defined as a person's perception and responses that result from the use or anticipated use of a product, system, or services (ISO 9241, 1998). The concept refers to all aspects of the interaction, including a person's behaviour, beliefs, preferences, and emotions. The concept of user experience encompasses both the affective and functional (cognitive) needs of the users (Hassenzahl and Tractinsky, 2006). While the functional needs refer to the usability of the product, the affective need is the emotion that occurs as a result of the interaction with the product, and it is part of the user experience (Zhou et al., 2010; Xu et al., 2011; Park et al., 2013). For the affective elements to be implemented, Hassenzahl and Tractinsky (2006) suggest that the needs of the user must be better understood, defined, and operationalised.

Forlizzi and Battarbee (2004) classified the existing frameworks for understanding user experience as product-centred, user-centred, and interaction-centred models. The product-centred frameworks (Alben, 1996; Jääskö and Mattelmäki, 2003) predominantly focus on the experience evoked by the product. They are mostly developed as guidelines to help designers to incorporate aspects that can evoke pleasurable experiences when designing the product. The usercentred frameworks (Mäkelä and Fulton, 2001; Hassenzahl, 2003) focus on the aspects of the user's behaviour that designers can incorporate into the design in order to facilitate the ease of use of the product. The interaction-centred frameworks (Forlizzi and Ford, 2000; Mäkelä and Mattelmäki, 2002; Overbeeke and Wensveen, 2003) focus on the experiences that the product evokes as a mediator between the designer and the user. Furthermore, Forlizzi and Battarbee (2004) have shown that the interaction-centred model is the most valuable according to their classification system, as it incorporates aspects of the product-centred and the user-centred frameworks for gaining insight into user experience.

Hekkert (2006) describes user experience as the entire set of effects that are elicited by the interaction between a user and a product, including the degree to which all senses are gratified (aesthetic experience), the meaning attached to a product (experience of meaning or usability), and the emotion that are elicited (emotional experience). People naturally use their cognitive, motor, and affective skills to interact with a product (Wensveen, 2005). The experience of meaning is linked to cognition; previous experience plays a great role in the association, interpretation, and retrieval of features from memory (Hekkert, 2006). A product that is designed with the user's previous experience in mind does what the user expects, with 
minimal cognitive effort and within the shortest possible time frame. Previous studies have used several usability measurement standards for evaluating user interfaces (Nielsen, 1993; Jordan, 1998, Park et al. 2013). The official usability measurement is based on effectiveness, efficiency, and satisfaction (ISO, 1998). The performance indicators commonly used are time on task for efficiency, accuracy for effectiveness, and preferences used for satisfaction measurement.

\section{RESEARCH METHODOLOGY}

The research plan for the current study consists of four phases. This comprises:
i. $\quad$ Understanding the user's needs.
ii. Developing the requirement specification.
iii. Designing/assembling and configuration of the product.
iv. Evaluation of the product.

\subsection{Understanding Users' Needs}

This process is essential in gaining insight into the users thinking while interacting with the product. In this research phase, a structured questionnaire and interview is proposed as the methods for gaining insight into the user's behaviour. The use of structured questionnaire is a valuable method for collecting evaluation information. In addition, it provides access to data from the user.

The interview method of data collection primarily extracts data orally from users. The use of the interview helps to investigate issues in depth. This is done in order to extract relevant information that may not be captured by the other method. This study adopts a structured approach for interviewing participants in order to aid consistency and to allow for the comparison of extracted information.

\subsection{Developing Requirement Specification}

Thereafter, requirement specification will be developed from the structured questionnaire and interview by the research team. The voices of customer that will be identified in the data will be converted to engineering characteristics.

The engineering characteristics will be presented to another set of participants proposed to be recruited for the second study to rank these characteristics in order of importance. Thereafter, Quality Function Deployment will then be used to rank the customer's needs and normalised using normalised weighting approach by the research team.

\section{3: Design/Assembly/Testing}

The third phase will involve designing/assembling and configuration of the product based on the data extracted from phase 2 above. The five most important characteristics from the quality function will therefore be used to design and configure the new alarm clock. This new alarm clock is proposed to address the salient needs of the users.

\subsection{Evaluation Phase}

The alarm clock that has been designed in phase 2 of the study will thereafter be evaluated with a conventional alarm clock available in the market using end users of the product. This will be done in order to check the performance of the participants with the use of the two alarm clocks (Designed clock against the conventional clock in the market) proposed for the study.

\section{STUDY DESIGN}

This section describes the implementation of the methodology adopted for the purpose of the research. Three separate studies were designed to address the research objectives. Study 1 was designed to develop a usage context through structured questionnaire and interview of participants recruited for the study. Study 2 was designed to manage, refine and rank the prevailing users' needs identified in the first study. The five most important ranking from study 2 was thereafter used to design the alarm clock by the research ream. The third study was designed to evaluate the new design against the conventional alarm clock available in the market.

\subsection{Study 1}

The study was designed to identify usage scenario from structured questionnaire and interview. This was done in order to understand users need and collate data from the structured questionnaire and interview from participants recruited in the study. The participants were asked to describe how to set an alarm time to $3.30 \mathrm{pm}$ with the alarm clock they have used in the past. The data were collated from the 36 participants recruited for the study based on structured questionnaire and interview methods used in the study.

Thereafter, the voices of customers were identified by the research team. These voices of customers were later transformed into engineering characteristics by the design team. Overall, the voices of customers identified were transformed into 17 engineering characteristics in the study. These include: easy to understand, durability of battery, voice recognition, shape, colour, size, material used for the product, weight, use of icon/words/both icon and words, location of buttons, clear description, multiple alarm setting, stiffness of the button, clear mapping (one button for one function), feedback, sound type, and volume control.

\subsection{Study 2}

The transformed voices of customer into engineering characteristic were presented to another set of 25 participants to rank in order of importance in the second study. The participants were told to rank the 17 items identified in the first study on the scale of 
1 to 5 , with 1 the most important to 5 the least important. At the conclusion of the study, the 25 participants recruited for the study ranked the 17 engineering characteristics in order of importance.
Thereafter, the designed team took the average of the ranking of the 17 items and re-ranked in the order of importance as shown in Table 1.

Table 1: Engineering Characteristic Ranked in Order of Importance

\begin{tabular}{|l|l|c|c|}
\hline S/N & Engineering characteristics & Average rank & Position \\
\hline 1 & Easy to understand & 1.56 & $4^{\text {th }}$ \\
\hline 2 & Durability of battery & 1.16 & $1^{\text {st }}$ \\
\hline 3 & Voice recognition & 2.08 & $12^{\text {th }}$ \\
\hline 4 & shape & 2.44 & $16^{\text {th }}$ \\
\hline 5 & colour & 2.76 & $17^{\text {th }}$ \\
\hline 6 & size & 2.12 & $14^{\text {th }}$ \\
\hline 7 & Material used for the product & 1.56 & $4^{\text {th }}$ \\
\hline 8 & weight & 2.08 & $12^{\text {th }}$ \\
\hline 9 & Use of icon/words/redundancy & 1.76 & $10^{\text {th }}$ \\
\hline 10 & Location of button & 1.68 & $8^{\text {th }}$ \\
\hline 11 & Clear description & 1.64 & $7^{\text {th }}$ \\
\hline 12 & Multiple alarm settings & 1.56 & $4^{\text {th }}$ \\
\hline 13 & Stiffness of the button & 1.68 & $8^{\text {th }}$ \\
\hline 14 & Clear mapping: one button for one function & 2.12 & $14^{\text {th }}$ \\
\hline 15 & feedback & 1.92 & $11^{\text {th }}$ \\
\hline 16 & Sound type & 1.44 & $3^{\text {rd }}$ \\
\hline 17 & Volume control & 1.28 & $2^{\text {nd }}$ \\
\hline
\end{tabular}

At the conclusion of the second study, the five most important characteristics out of the 17 identified as ranked by the participants in the study is shown in Table 2. They include durability of battery; volume control, sound type, easy to understand/material used for the product/multiple alarm setting and clear description.

Table 2: The Five Most Important Engineering Characteristics

\begin{tabular}{|l|l|c|c|}
\hline S/N & Engineering characteristics & Average rank & Position \\
\hline 1 & Durability of battery & 1.16 & $1^{\text {st }}$ \\
\hline 2 & Volume control & 1.28 & $2^{\text {nd }}$ \\
\hline 3 & Sound type & 1.44 & $3^{\text {rd }}$ \\
\hline 4 & $\begin{array}{l}\text { Easy to understand/material used for the product/multiple } \\
\text { alarm setting }\end{array}$ & 1.56 & $4^{\text {th }}$ \\
\hline 5 & Clear description & 1.64 & $5^{\text {th }}$ \\
\hline
\end{tabular}

Finally, the five most important characteristics identified as important in the study were thereafter used by the research team to design and configure the hardware of the new alarm clock shown in Figure 1 below. 


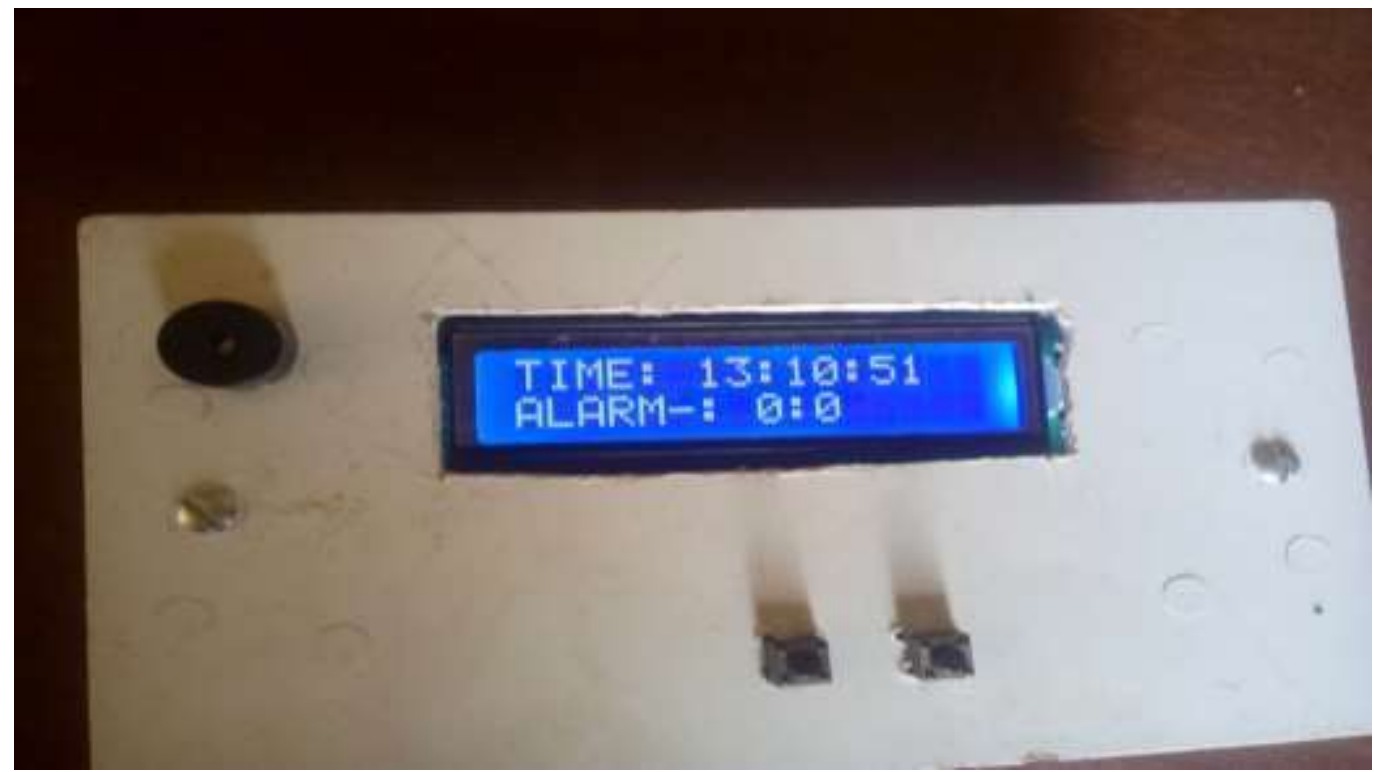

\section{3: study 3}

Finally, the last study was conducted to test the performance of the designed alarm clock as against the conventional clock available in the market. Twenty participants were recruited for the third study. They were given clear instruction to complete a simple task using the designed clock and the conventional clock available in the market. They were

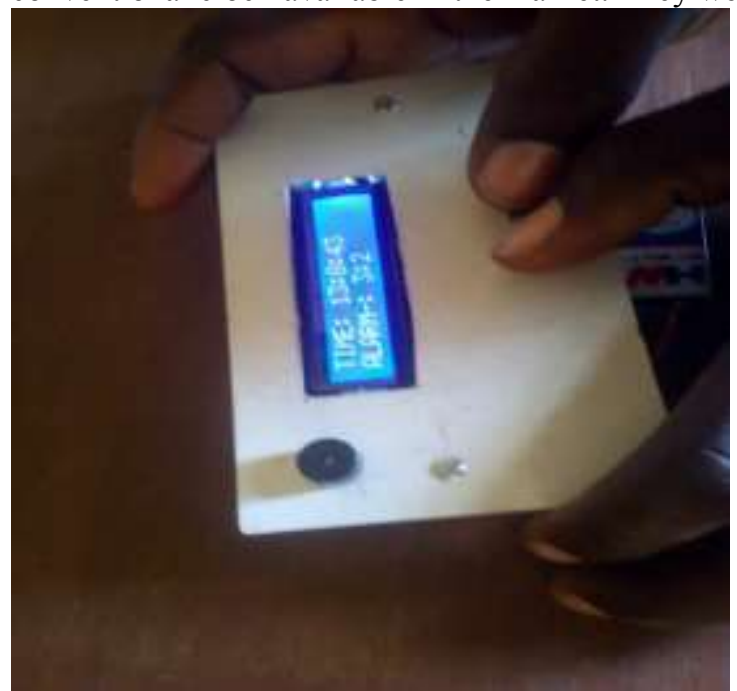

Figure 2A: Designed alarm clock

\section{EVALUATION RESULTS}

The hypothesis tested is that the time to complete a task will be quicker with fewer errors for the majority of the participants that uses the designed alarm clock (alarm clock 1) in the study as against the selected conventional alarm clock (alarm clock 2) in the market.

To test this hypothesis, participants that successfully completed the task were grouped using told to use the two alarm clocks to set the alarm time to $1.30 \mathrm{pm}$. They were observed while completing the task. The entire interactions were recorded. Figures $2 \mathrm{~A}$ and $2 \mathrm{~B}$ shows the two alarm clocks used in the study. At the completion of the task, the time to complete the tasks and number of errors made were processed from the data.

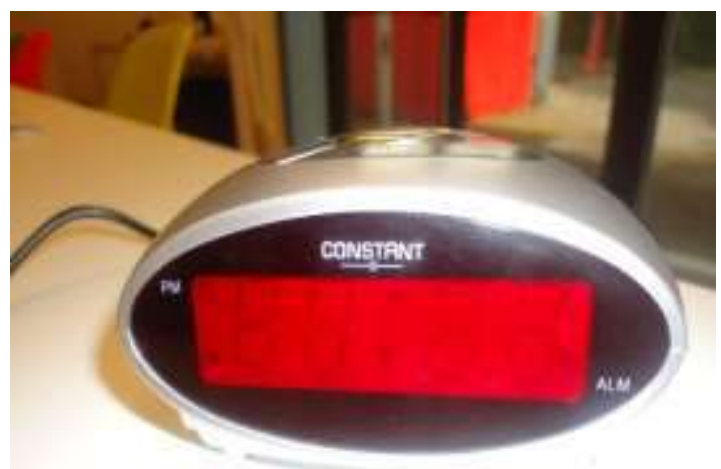

\section{Figure 2B: Conventional alarm clock}

the two alarm clocks used in the study. It is expected that the majority of the participants will significantly perform better on the task for the designed alarm clock as against the conventional clock available in the market.

Statistical analysis was then conducted in order to examine how the performance indices affect the use of the two alarm clocks used in the study 
using SPSS 20.0. The homogeneity of variance test was conducted using Levene's test of equality of variance. A Levene's test result of less than 0.05 indicated that homogeneity of variance was violated; hence a Welch correction test was used for dependent variables. A Levene's test of more than 0.05 indicated that homogeneity of variance was observed in the variable; hence a normal parametric test was conducted (Laerd, 2013). An independent t-test was

Table 3: Mean and Standard Deviation Time on Tasks and Errors in the Two Groups

\begin{tabular}{|l|l|l|l|l|l|}
\hline \multirow{2}{*}{ Variables } & \multirow{2}{*}{ No } & \multicolumn{2}{|c|}{ Clock 1 } & \multicolumn{2}{c|}{ Clock 2 } \\
\cline { 3 - 6 } & & Mean & SD & Mean & SD \\
\hline Time (s) & 20 & 102.65 & 9.99 & 130.65 & 7.27 \\
\hline Error & 20 & 1.25 & 0.63 & 1.70 & 0.86 \\
\hline
\end{tabular}

An independent t-test was run to determine if there were significant differences in times to complete the task and errors made in the two groups (alarm clock 1 and 2). For time on task, homogeneity of variance was maintained, as assessed by the Levene test of equality of variance $(\mathrm{p}=0.09)$, so normal parametric test was conducted. For the variable time on task and alarm clock 1 and 2, the results revealed that a statistical difference existed between the participants' time to complete the task in the two groups (alarm clock 1 and 2 ): $\mathrm{t}(38)=2.76 \mathrm{p}<0.05$.

Similarly, for the number of errors made while completing the task, homogeneity of variance was maintained, as assessed by the Levene test of equality of variance $(\mathrm{p}=0.22)$, so normal parametric test was conducted. For the variable errors made while completing the task and types of alarm clock, the results revealed that a statistical difference existed between the participants' time to complete the task in the two groups (alarm clock 1 and 2$): \mathrm{t}(38)=2.00$ $\mathrm{p}<0.05$.

These results indicate that participants were significantly quicker in completing the task with the designed alarm clock (alarm clock 1) as against the selected alarm clock (alarm clock 2) available in the market used in the study. Similarly, the errors made by the participants while completing the task were significantly fewer with the designed alarm clock (alarm clock 1) as against the selected alarm clock (alarm clock 2) in the market used in the study.

\section{CONCLUSION}

The results presented in the study suggest that the proposed approach can improve the usability of the product. Furthermore, the approach developed in the study can easily strengthen the designer's and users relationship, If the effects observed from the users are not those that are intended by the designer, changes can be recommended in order to improve the interpretation of the product features by the users.

Specifically, the results from the analysis of the performance data of the users clearly shows a used to determine if there were significant differences in the two variables (time to complete task and errors) in the two groups (alarm clock 1 and 2) in the study.

\subsection{Dependent Variables}

The mean and standard deviation time on task and errors were computed for the two alarm clocks used in the study, as shown in Table 3. significant difference exist between time to complete task and error made using the designed alarm clock compared to the conventional chosen for the study. This result demonstrates the utility of the approach for the design of product. Overall, the results validated the hypothesis developed in the study.

\section{Acknowledgement}

Funding for this research work was provided by the Tertiary Education Trust Fund (TETFund) based in Nigeria. The research team also wishes to appreciate all staff of the department of Mechanical Engineering, Edo State Polytechnic, for their technical supports in the course of conducting this research work .

\section{REFERENCES}

1. Alben, L. (1996). Quality of Experience. Defining the criteria for effective interaction. Interactions, vol. 3 (3), pp.11-15.

2. Asikhia, O. K., Setchi, R., Hicks, Y. and Andrews, W. (2015). Conceptual Framework for Evaluating Intuitive Interactions based on Image Schemas. Interacting with Computers, doi:10.1093/iwc/iwu050.

3. Blackler, A. and Hurtienne, J. (2007). Towards a Unified View of Intuitive Interaction: Definition of Models and Tools across the World. MMI-Interaktiv, vol. 13, pp. 37-55.

4. Forlizzi, J. and Battarbee, K. (2004). Understanding Experience in Interactive Systems. Proceedings of the 2004 Conference on Designing Interactive Systems: Processes, Practices, Methods, and Techniques, pp. 261-268. New York: ACM.

5. Forlizzi, J. and Ford, S. (2000). The Building Blocks of Experience: An Early Framework for Interaction Designers: Proceedings of Designing Interactive Systems: Processes, Practices, Methods, and Techniques, pp. 419-423. New Tork: ACM.

6. Hassenzahl, M. (2003). The Thing and I: Understanding the Relationship between User and Product. In M. Blythe, C. Overbeeke, A. F. Monk, and P. C. Wright, Funology: From Usability to Enjoyment, pp. 31-42. Dordrecht: Kluwer. 
7. Hassenzahl, M. and Tractinsky, N. (2006). User Experience-A Research Agenda. Behaviour and Information Technology, vol. 25(2), pp. 91-97.

8. Hekkert, P. (2006). Design Aesthetics: Principles of Pleasure in Product Design. Psychology Science, vol. 48(2), pp. 157-172.

9. ISO 9241-11. (1998). Ergonomics Requirements for Office Work with Visual Display Terminals - Part 11: Guidance on Usability. Geneva. International Organisation for Standardisation.

10. Jääskö, V. and Mattelmäki, T. (2003). Observing and Probing. In Proceedings of the DPPIO3 Conference, pp. 126-131.

11. Jordan, P.W. (1998). Introduction to Usability. London: Taylor and Francis.

12. Laerd Statistics, (2013). Available at: https://statistics.laerd.com/spss-tutorials/one-wayanova-using-spss-statistics.php. (Accessed 10/12/2014).

13. Mäkelä, A. and Fulton Suri, J. (2001). Supporting Users Creativity: Design to Induce Pleasurable Experiences. In M. Helander, and H. M. Khalid (Ed.), Proceedings of the Conference on Affective Human Factors pp. 387-391. London: Asean Academic Press.

14. Mäkelä, A. and Mattelmäki, T. (2002). Collecting Stories on User Experiences to Inspire Design - A Pilot (Green, W.S., Jordan, P.W. eds) Pleasure with Product. Taylor and Francis, pp. 333-344.

15. Nielsen, J. (1993). Usability Engineering. Morristown, NJ: AP professional.

16. Norman, D. A. (1993). Things that Make us Smart. Defending Human Attributes in the Age of Machine. Reading M.A Addison Wesley Publishing Company.

17. Overbeeke, C.J. and Wensveen, S.A.G. (2003). Reflection on Pleasure: From Perception to Experience, from Affordances to Irresistible. In: Proceedings of the DPPIO3 Conference, pp. 92-97.

18. Park, J., Hans, S.H., Kim, H.K., Choi, Y. and Park, $W$. (2013). Developing Elements of User Experience for Mobile Phones and Services: Survey, Interview and Observation Approaches. Human Factors and Ergonomics in Manufacturing and Service Industries, vol. 23(4), pp. 279-293.

19. Rettig, M. (1999(. Nobody Reads Documentation: Communication of the ACM, 34 (1), 19-24.

20. Wensveen, S. A. G. (2005). A Tangibility Approach to Affective Interaction. University of Technology, Delft.

21. Xu, Q., Zhou, F. and Jiao, J. R. (2011). AffectiveCogntive Modelling for User Experience with Modular Coloured Fuzzy Petri Nets. ASME Journal of Computing and Information Science in Engineering, vol. 11(1), 011004. Doi:10.111511.3563047.

22. Zhou, F., Jiao, R.J., Schaefer D. and Chen S. (2010). Hybrid association mining and refinement for affective mapping in emotional design. ASME Journal of Computing and Information science in Engineering, vol. 10(3) pp. 031010/1-9. 